\title{
Corrosion potential in oral cavity
}

\author{
Vladimir Panov, Martina Markova
}

\author{
Department of Conservative Dentistry and Oral \\ pathology, Faculty of Dental Medicine, Medical \\ University of Varna;
}

\begin{abstract}
Different metal alloys are used for restoration in dental practice. As a result of electrochemical processes, metal objects in the oral cavity become electrically charged and can lead to generation of corrosion potential. This phenomenon can be manifested as pathogalvanism and is characterised by complaints of metallic taste, paraesthesia, tingling, burning, various inflammatory processes, etc. Its clinical manifestations are diverse and quite common. The corrosion potential of dental alloys in the oral cavity depends on their composition, the degree of polishing, the structural changes occurring during their placement and the time elapsed since their placement.

In 42 patients with metal restorations, we found that dental amalgam predominates amongst the metals used to repair lost hard dental tissue, mainly in molars. $78.4 \%$ of the metal objects in the oral cavity are amalgam, as $78 \%$ of restorations are on molars, and $19 \%$ on premolars. The majority of metal restorations are in the upper jaw (57\%), $41 \%$ of patients have only one metallic restoration, $14 \%$ have over three metal objects. Very few of the corrosion potential values exceed the norm - only $4 \%$ of the samples tested, despite the presence of more than one metal in the same oral cavity $-17 \%$ of the subjects. We found no patient with increased total corrosion potential. The presence of pathogalvanism with elevated values are seldom.
\end{abstract}

Keywords: dental amalgam, Oral galvanism, corrosion potential, metal

\section{Introduction}

Many different alloys are used to restore lost hard dental tissue and they remain in the human body for a long time. Galvanic current in the oral cavity can be produced by the direct contact between two metals or through a liquid medium, where saliva serves as an electrolyte. This is also facilitated by the high content of ions in it: sodium, chloride, phosphate, carbonate, hydroxyl, etc. As a result of electrochemical 
processes in the oral cavity, metals become electrically charged. In some cases, this is completely harmless, but in others it may turn into permanently active pathological factors and cause various diseases in the maxillo-facial area or in other parts of the body, i.e. so-called pathogalvanism. The corrosion potential of dental alloys in the oral cavity depends mainly on their composition, the degree of polishing, as well as structural changes in the alloys that have occurred during heat treatment and the time elapsed since their placement (Panov VI, 2016). Some studies have observed that recently placed silver amalgam fillings, metal bridges and crowns have a higher electronegative corrosion potential. Precise polishing of all silver amalgam restorations strongly reduces the corrosion potential and increases their corrosion resistance.

The presence of two or more metal objects with different corrosion potentials in the oral cavity yields a potential difference - electromotive force, and when they are connected, either directly or through the mucous membrane and saliva, galvanic current is produced in the mouth. It accelerates the corrosion of metal alloys and can act pathologically. The strongest are the electromotive tensions between silver amalgam restorations and metallic prosthetic restorations (gold and cobalt-chromium-molybdenum alloys).

Clinical manifestations of pathogalvanism are varied and frequent. They are subjective complaints burning and sore feeling on the tongue and cheeks, metallic, sour or bitter taste, dry mouth, and objectively established oral diseases - recurrent mouth sores, glositis, gingivitis, stomatitis, etc. Less commonly reported problems are reduced immune levels, disorders of the trigeminal nerve, insomnia, vertigo, memory loss (Kiselova-laneva A, 2001; Panov Vl, 2016).

\section{Aim}

The aim of our study was to investigate the corrosion potential in healthy complaint-free patients with metal objects in the oral cavity.

\section{Materials and methods}

We tested the corrosion potential of 42 consecutive patients aged 21 to 72 years old who visited the faculties of dental medicine in Varna and Sofia. All subjects had fixed metal restorations. They didn't have any complaints about them.

The measurement of corrosion potentials was carried out with a Dentotest Six device. Immediately before each measurement, the ends of the two probes were cleansed with alcohol. An important condition is that the patient should not brush the teeth, consume food, liquids, or smoke for 12 hours before the test. Any saliva or food residues are removed with tweezers and cotton, no drying with air jet.

One electrode is placed on the metal object (amalgam obturation, metal crown, bridge body of metal, etc.), and the other - on the apical part of the oral mucosa above the tooth being examined. For base metals the negative pole rests on the examined metal and the positive electrode - on the oral mucosa, for precious ones - the other way round. On the screen of the machine, the metal values are negative (-), and the precious metals - positive (+). The results obtained for each patient are mapped on the scheme to see 
which metal objects give the highest electronegative corrosion potential and between which there is a high electromotive force.

Adopted normal values are from 100 to $150 \mathrm{mV}$ for each object, and total metal corrosion potential for all objects in the oral cavity must be within $1000 \mathrm{mV}$ (after I. Todorov.) or $1500 \mathrm{mV}$ (after P. Bothushanov), and according to some authors - up to $600 \mathrm{mV}$ (A. Kisselova). All metal objects with corrosion potential above these values and in the presence of pathological manifestations must be removed and replaced with other suitable materials (Semerdjieva M, 1994; Kucerová H, 2003).

\section{Results}

We established presence of 88 separate metal objects in the oral cavity of the test group of patients -12 of them were metal-ceramic restorations, 3 - metal prosthetic restorations, 4 - golden crowns and 69 amalgam restorations. What stands out is the definitely more common application of dental amalgam comparing to all other metals used in dental practice (fig. 1 and 2).

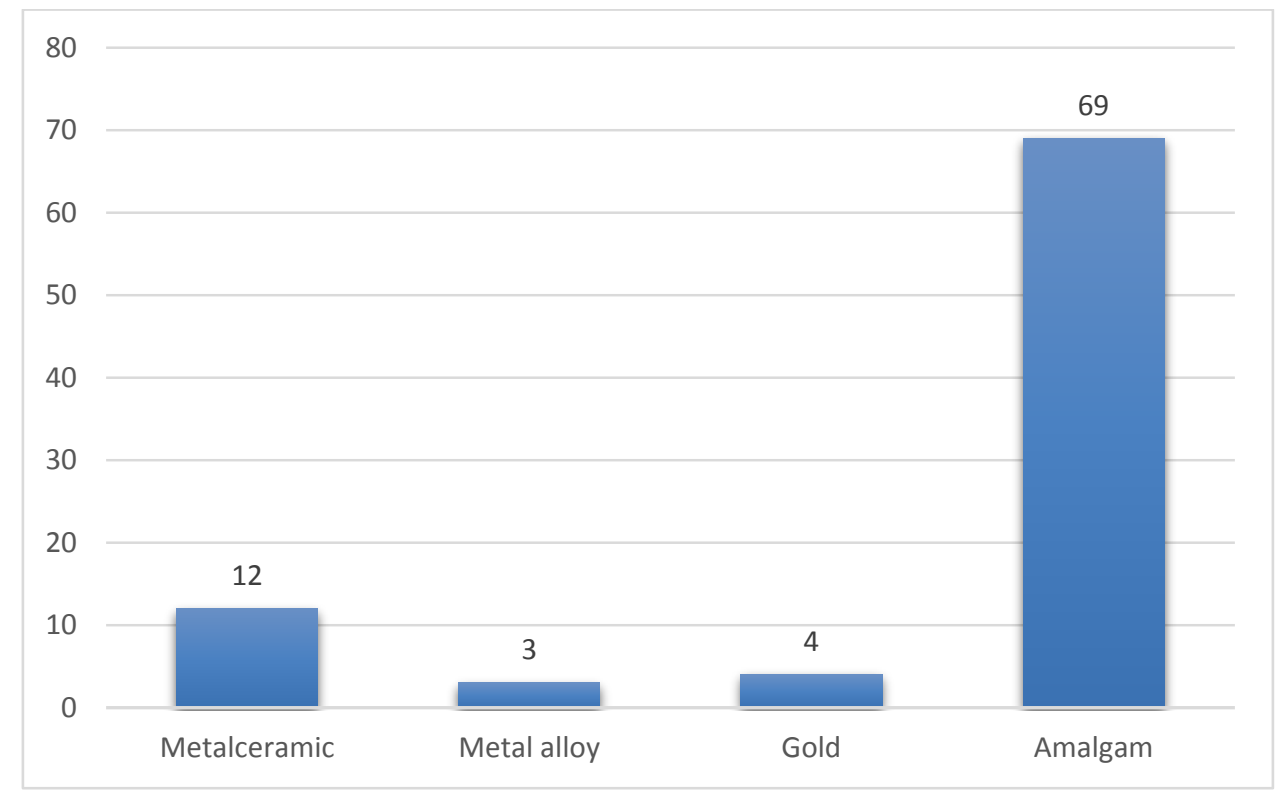

Fig. 1 Metals in the oral cavity established by the study 


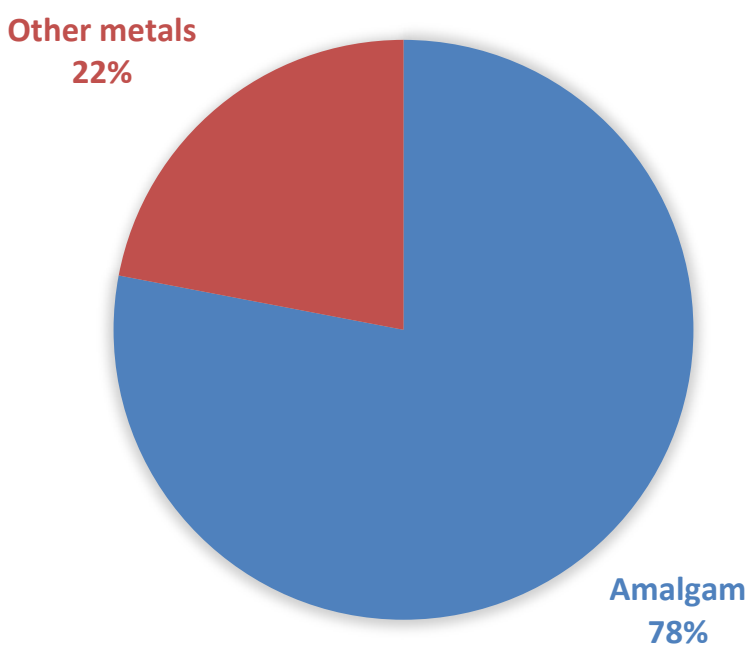

Figure 2 Proportion of dental amalgam comparing to other metals

Table 1. Number of metal objects by teeth

\begin{tabular}{|l|l|}
\hline No. of teeth & Number of metal objects \\
\hline 14 & 3 \\
\hline 15 & 5 \\
\hline 16 & 16 \\
\hline 17 & 3 \\
\hline 18 & 1 \\
\hline 24 & 1 \\
\hline 25 & 4 \\
\hline 26 & 15 \\
\hline 27 & 2 \\
\hline 34 & 1 \\
\hline 35 & 2 \\
\hline 36 & 14 \\
\hline 37 & 3 \\
\hline 44 & 1 \\
\hline 46 & 12 \\
\hline 47 & 4 \\
\hline 48 & 1 \\
\hline
\end{tabular}


Our results show that all the metal objects used for restoration of lost hard dental tissues are in the posterior teeth. $78.41 \%$ were on molars and $19.31 \%$ on premolars. Only $2(2.27 \%)$ of the replacements were on wisdom teeth (table 1 and 2).

Table 2. Distribution of metal objects by teeth

\begin{tabular}{|l|l|l|l|l|l|}
\hline & $\begin{array}{l}\text { First } \\
\text { premolars }\end{array}$ & $\begin{array}{l}\text { Second } \\
\text { premolars }\end{array}$ & First molars & $\begin{array}{l}\text { Second } \\
\text { molars }\end{array}$ & Third molars \\
\hline Number & 6 & $\mathbf{6}$ & 57 & $\mathbf{1 2}$ & $\mathbf{2}$ \\
\hline$\%$ & $\mathbf{6 . 8 1 \%}$ & $\mathbf{1 2 . 5 \%}$ & $\mathbf{6 4 . 7 7 \%}$ & $\mathbf{1 3 . 6 4 \%}$ & $\mathbf{2 . 2 7 \%}$ \\
\hline
\end{tabular}

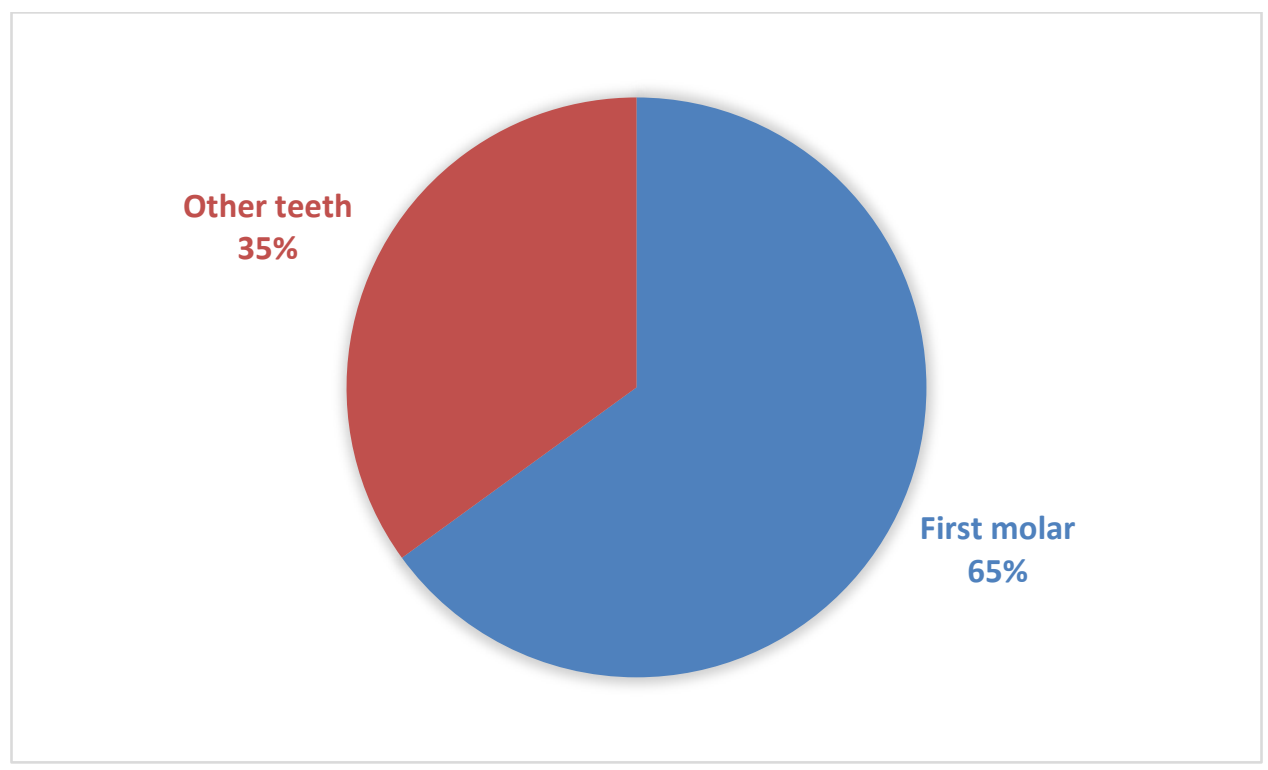

Fig. 3 Presence of metal objects

We found that nearly $2 / 3$ of metal restorations are on first permanent molars (fig. 3 ). 


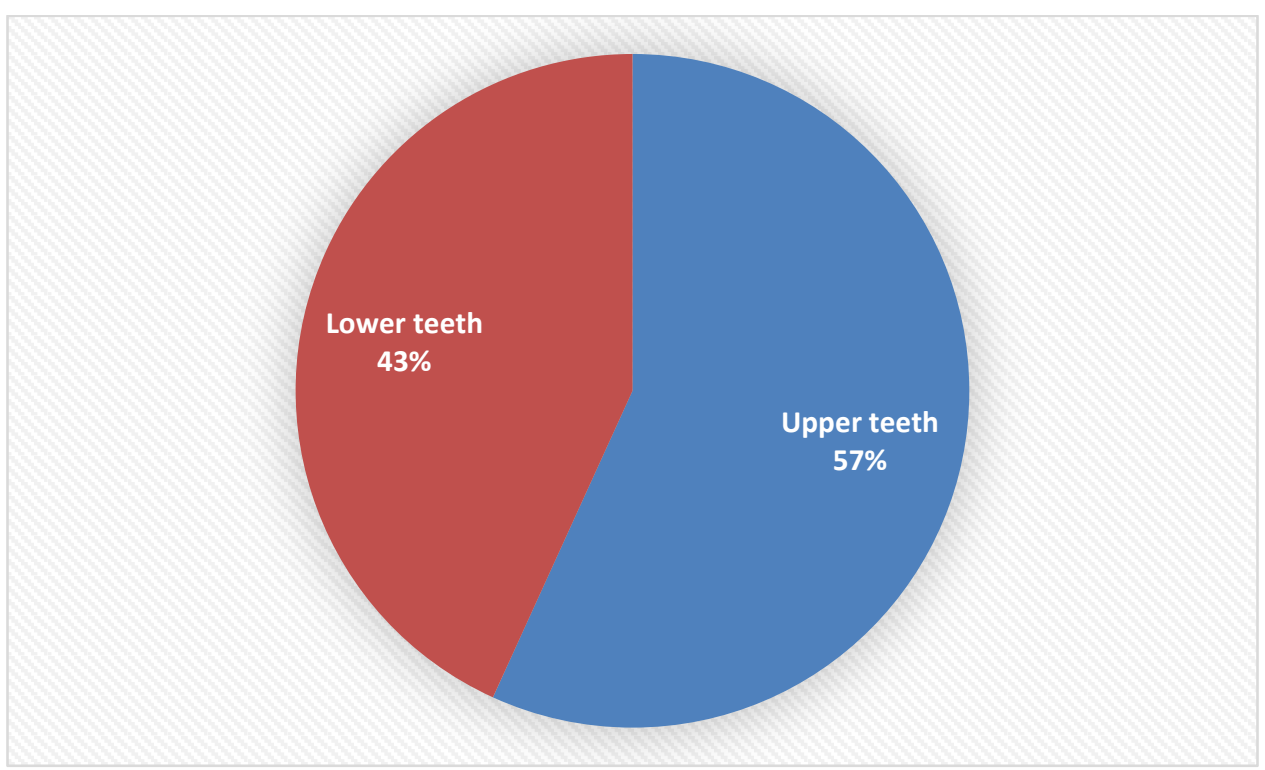

Fig. 4 Ratio of top/bottom teeth with metal restorations

Our study shows more frequent application of metal on upper teeth - 56.8\%. Just $43.2 \%$ of metal restorations are on the lower teeth. This is understandable, considering the aesthetic requirements of some of the patients (fig. 4).

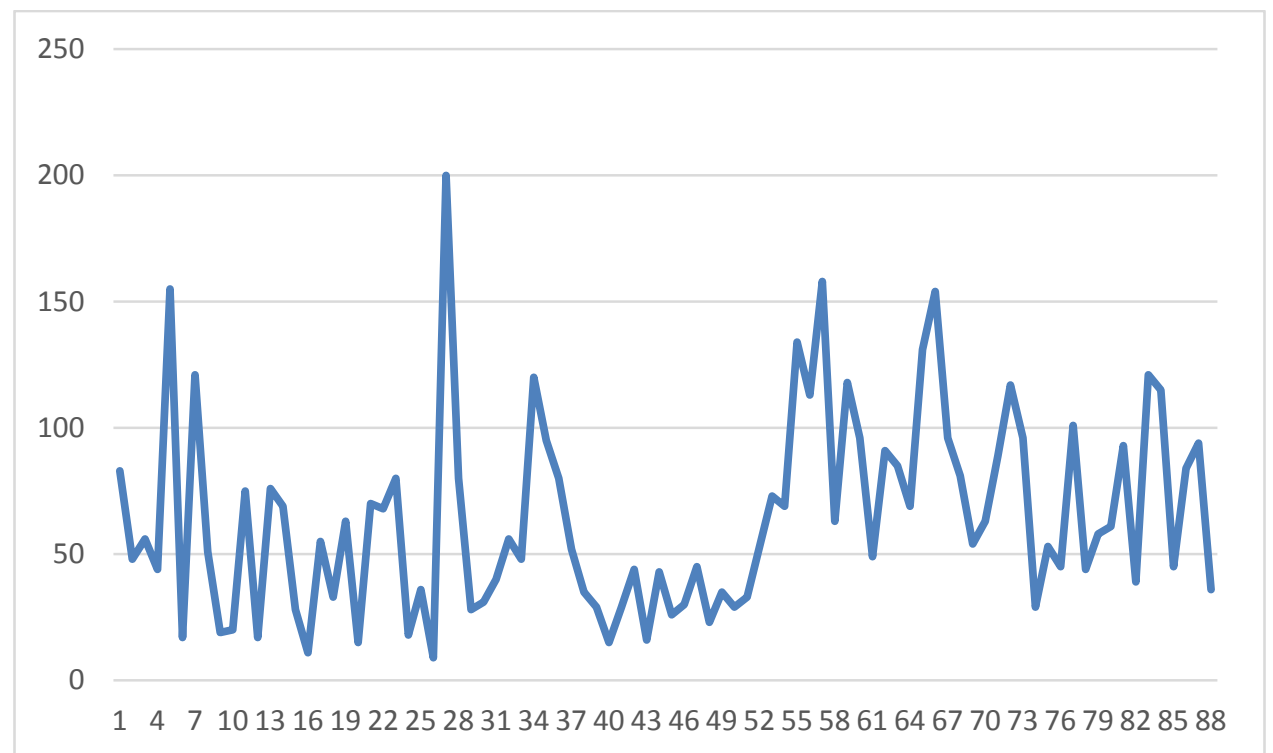

Fig. 5 Corrosion potential values established by the study in $\mathrm{mV}$, 88 samples

The average value of measured corrosion potentials was 64.42 , rank 9-200, SD \pm 38.91 (fig. 5). 
Only 4 of our samples were beyond $150 \mathrm{mV}$. In 84 cases results were within range (fig. 6).

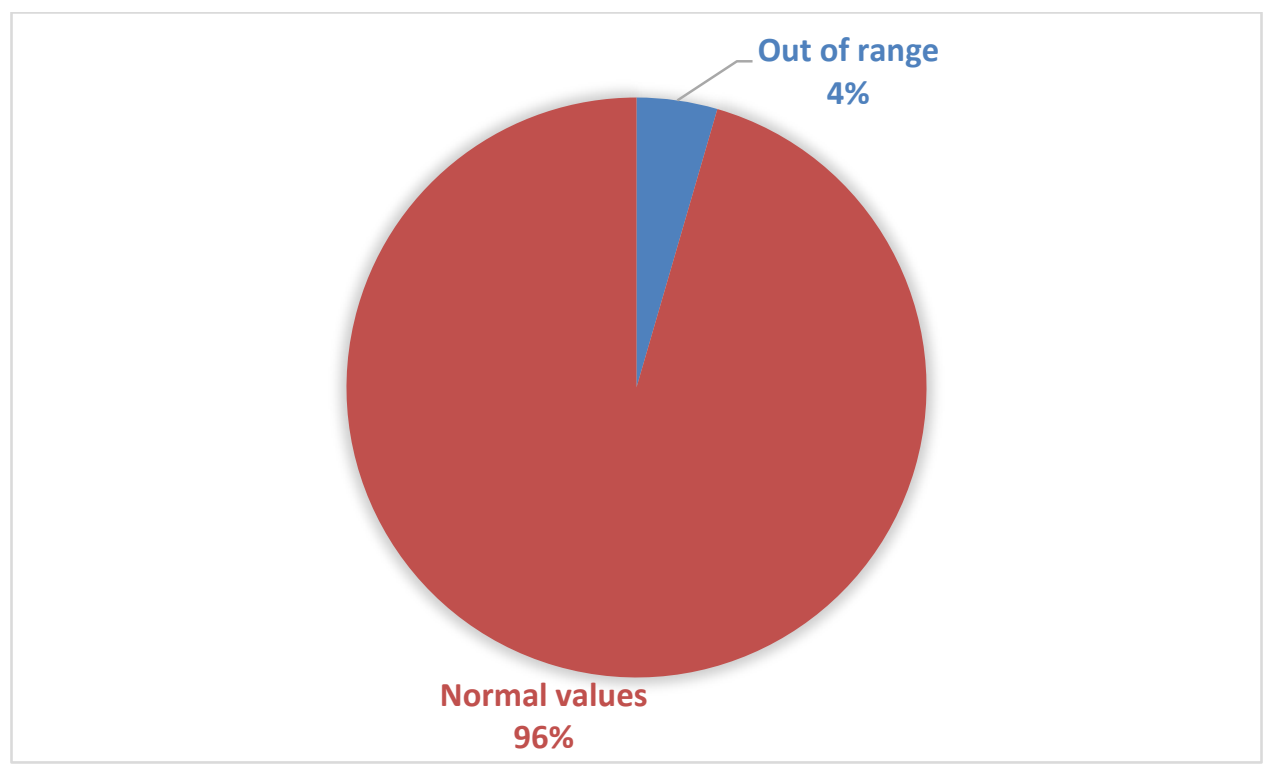

Fig. 6 Established corrosion potential values within and outside the norm

Corrosion potential values very rarely exceeded the norm. Total corrosion potential values for all objects in the oral cavity exceeding the norm were not observed in any of the subjects. This is most likely due to the high oral tolerance to metals.

Table 3. Number of metal restorations by patient

\begin{tabular}{|l|l|l|l|l|}
\hline & $\begin{array}{l}\text { With one metal } \\
\text { restoration }\end{array}$ & $\begin{array}{l}\text { With two metal } \\
\text { restorations }\end{array}$ & $\begin{array}{l}\text { With three metal } \\
\text { restoration }\end{array}$ & $\begin{array}{l}\text { With more } \\
\text { than } \\
\text { metal } \\
\text { restorations }\end{array}$ \\
\hline number & 17 & 13 & 6 & 6 \\
\hline$\%$ & $41 \%$ & $31 \%$ & $14 \%$ & $14 \%$ \\
\hline
\end{tabular}




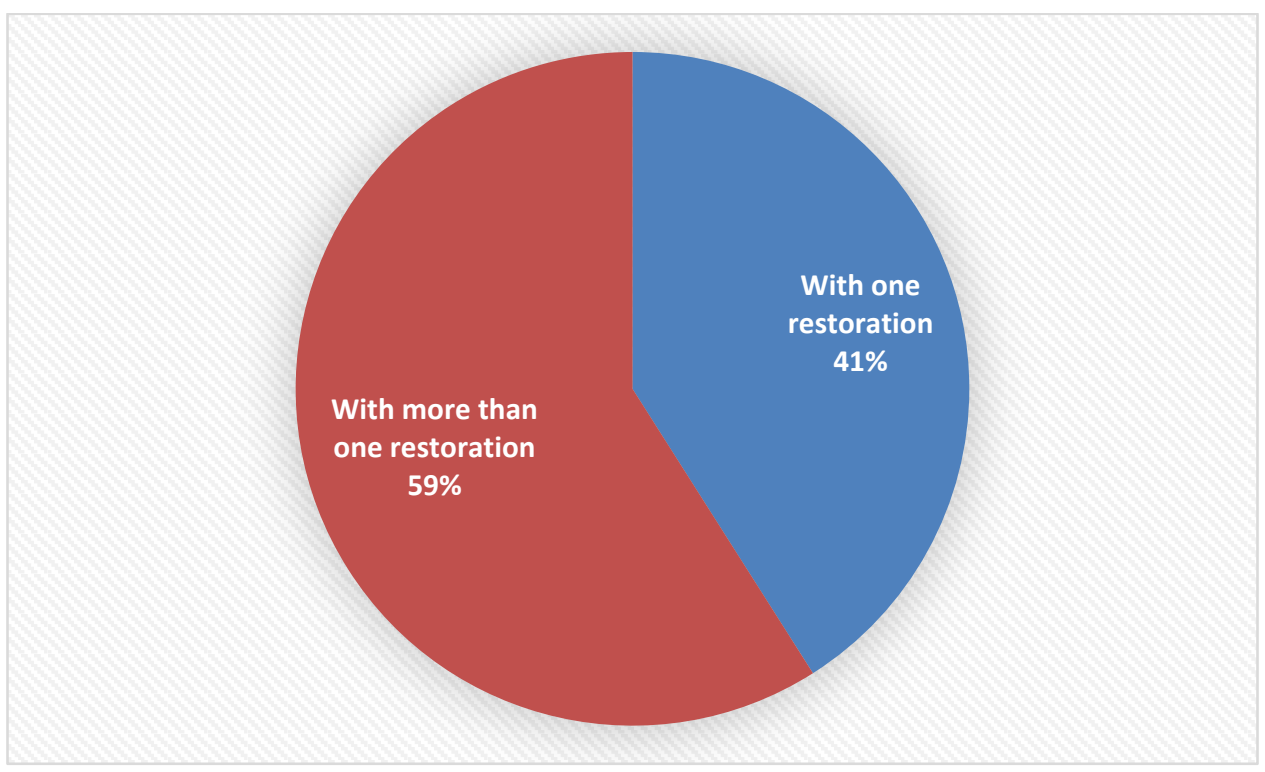

Fig. 7 Number of metal objects in each oral cavity

Presence of different metals in the mouth.

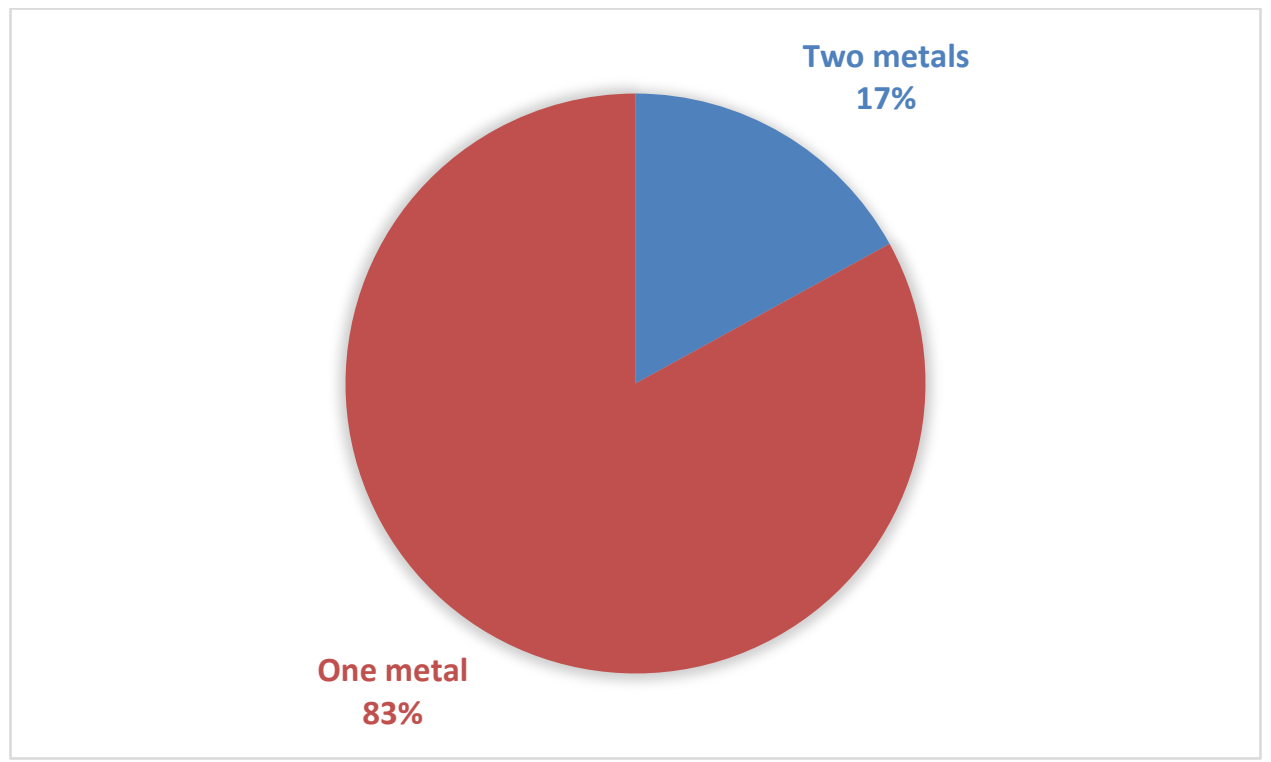

Figure 8. Number of metals in an oral cavity in patients surveyed

We found that 7 patients had more than one type of metal in the mouth. This accounted for nearly one-fifth of the people with metal in the oral cavity (fig. 8).

Table 4. Corrosion potentials with different number of metal restorations in one mouth. 


\begin{tabular}{|l|l|l|l|l|l|}
\hline & 1 metal object & 2 metal objects & 3 metal objects & 4 metal objects & 5 metal objects \\
\hline Average & $\mathbf{5 3 . 8 2}$ & $\mathbf{7 9 . 3 0}$ & $\mathbf{6 6 . 5 6}$ & $\mathbf{4 3 . 0 8}$ & $\mathbf{7 0 . 9 3}$ \\
\hline Standard deviation & 25.02 & 44.78 & 39.81 & 24.35 & 39.06 \\
\hline Rank & $15-96$ & $15-158$ & $28-200$ & $11-76$ & $17-155$ \\
\hline
\end{tabular}

We compared the values obtained by us with the number of metal objects present in the mouth of each patient. Highest average values for each metal object were found in patients with 2 metal restorations, while the lowest values were in patients with 4 different metal objects. This study showed that the number of metal objects did not affect the recorded corrosion potential values. We did not observe major changes of minimum or maximum values in the different groups.

\section{Conclusions}

The study showed that dental amalgam is applied as a restorative material for defects of dental structures more and more often, which confirms our previous research (Markova M, 2016, Markova M, 2015). Dental amalgam restorations of lost dental tissues predominated and were mainly used on the upper first molars. Very few of the corrosion potential values of our tested patients exceed the norm - only $4 \%$. The survey showed that the presence of pathogalvanism with exceeding values was rare. We also found that a large part of the patients had only one metal restoration (41\%). This was one of the factors contributing to the rarity of the condition. Nevertheless, the majority of subjects - $59 \%$ had more than one metal restoration, which was a precondition for the progress of electrical currents. About a third of the subjects had two metal objects and $14 \%$ had 3 or more metal objects. Although it was not recommended, we found relatively high presence of more than one metal in the same oral cavity - in $17 \%$ of the subjects. In none of the subjects did the total corrosion potential for all objects in the oral cavity exceed the standard values. The number of metal objects in the oral cavity did not affect the corrosion potential values we recorded.

\section{References}

1. Allergology and oral medicine. Principles and practices, Kisselova-laneva A, B. Petrunov, "Ivan Sapundjiev", 2013, 340 s., ISBN 978-954-9971-62-0(in Bulgarian)

2. Kisselova-laneva. Dental allergology and focal diagnostic. Measurement of the elektropotencial in oral cavity, Gutenberg, 2001, 94-97.(in Bulgarian)

3. Markova M, Panov VI, Georgiev G, Vicheva Z, Dental amalgam-clinico-epidemiological aspects, Varna Medical Forum, 5, 2016, issue 2, 210-213. (in Bulgarian)

4. Panov VI, Adverse reactions in the mouth during use of dental amalgam, Varna Medical Forum, 2016, 5(1), 77-81. (in Bulgarian)

5. Panov VI, M. Markova, History of dental amalgam, Varna Medical Forum, 2016, 5(1), 119-123. (in Bulgarian)

6. Panov VL, Reactions in the oral cavity in use of dental amalgam, Biocompatibility in oral medicine, Medinform, 2016, 225-228. (in Bulgarian)

7. Semerdjieva M, A. Kisselova-laneva. Effect of some common diseases on the korozion potential of the metal constructions - Dentistry, 1994, 1, 14-16. 
8. Kucerová H, Dostálová T, Procházková J, Bártová J, Himmlová L, Influence of galvanic phenomena on the occurrence of algic symptoms in the mouth, Gen Dent. 2002, 50(1): 62-65.

9. Markova M, G. Georgiev, VI. Panov, Z. Vicheva, A. Kisselova, Use of dental amalgam, 14 - 17 May 2015, Varna, Bulgaria, Poster

\section{Corresponding author:}

Vladimir Panov,

Department of conservative dentistry and oral pathology

Faculty of dental medicine

Medical University of Varna

email: vl_panov@abv.bg 